\title{
Using the Creative Cognition Approach in Essay Assignments in Leadership Education
}

\author{
Tim Atkinson, Ed.D. \\ University of Arkansas for Medical Sciences
}

\begin{abstract}
This application brief covers, "The Final Question", an alternative essay design that encourages the learner to think creatively in Ph.D. Organization Theory or Leadership courses. "The Final Question" asks, "Do leaders change organizations or do organizations change leaders?" It is a simple question, but only the first in a series of prompts that guide Ph.D. learners on a path to become more creative thinkers. First, the learner must explore two knowledge domains in detail: Leadership Theory and Organization Theory. Next, the learner must combine information from each domain to create novel ideas about leadership action in organizational contexts. Finally, the learner must name the new concepts and share them with other learners.
\end{abstract}

\section{Issue Statement}

"The Final Question" asks, "Do leaders change organizations or do organizations change leaders?" It is indeed a simple question, but only the first in a series of prompts that guide Ph.D. learners on a path to become more creative thinkers. To answer the question, the learner must first explore two knowledge domains in detail: Leadership Theory and Organization Theory. Next, the learner must combine information from each domain to create novel ideas about leadership action in organizational contexts. The approach is backed by cognitive learning theory and taps Bloom's taxonomy at the creativity level (Anderson et al., 2001; Bloom, 1956). More specifically, the exercise is backed by creative cognition, concept combination, and concept modification theories (Estes \& Ward, 2002; Finke, Ward, \& Smith, 1992; Steven, Ward, \& Finke, 1995; Ward, 2001; Ward, Patterson, \& Sifonis, 2004; Ward, 2008; Ward \& Wickes, 2009). Anecdotally, students found the exercise challenging with self-reports of better understanding of organizational dynamics.

I took this approach because, first, when Ph.D. learners took my foundation course in Organizational Theory, they often had trouble recalling their Leadership Theory from the previous semester. I needed them to know Leadership Theory to make the Organization course more meaningful. Second, I believe a Ph.D. program should teach learners how to generate new concepts or modify existing concepts to create new knowledge from broad categories. After all, this is what learners do at the dissertation phase when they make the transition from didactics to independent scholars. This reinforces learning from previous courses and teaches learners to integrate ideas from across the curriculum. Finally, Priority I of the National Leadership Education Research Agenda (NLERA) encourages creativity by suggesting the combination of concepts from different disciplines and moving away from the taken-for-granted approaches to teaching and learning (Jenkins \& Dugan, 2013). 


\section{Learner Profile}

Most learners enter our Ph.D. program with a Master's degree, most of them work either full or part-time, and most have families. I wanted to encourage their development by opening the class to these experiences, cognitive maps, and their desire to pursue learning at this stage of their lives. It was also important to entice them to transform their ways of thinking about static theories and assumptions. The "Final Question" includes the appropriate prompts for creative thinking, and provides the flexibility needed for the self-directed style of an adult Ph.D. learner. The tool is also grounded in the cognitive perspective that helps us understand how concepts are developed behind the scenes, so to speak, and to guide the learner to transform the way they know, how they know and how to change static concepts into modified or new ones (Merriam \& Bierema, 2014).

One of the prime objectives of a Ph.D. program is to guide the scholar toward independence and to equip them with the tools they need to create new knowledge or modify existing knowledge. The new taxonomy of learning replaces the word "synthesis" with the word "creativity" for excellent reason, because "creativity" explains the process of generating meaning and outcomes instead of the simple explanations of relationships in existing knowledge (Krathwohl \& Anderson, 2010). We will touch on the theory of design, including self-directed learning (Merriam \& Bierema, 2014), creative cognition, conceptual combination and concept modification theories.

\section{Literature Review}

Creativity in Leadership Education. Scholars in Leadership Education encourage creativity for leaders, followers, scholars, and learners (Baublits, 2014; Paxton \& Van Stralen, 2014). Priority I of the National Leadership Education Research Agenda (NLERA) encourages creativity by suggesting the combination of concepts from different disciplines and moving away from the taken-for-granted approaches to teaching and learning (Jenkins \& Dugan, 2013). We seem to do a great job with discussion, group activities, essays, research papers and critiques. Paxton and Van Stralen (2015) suggested teachers consider using "Practices that Foster a New Mindset" in learners such as collaboration in leadership, noting that collaboration builds the environment for creativity. Baublits (2014) reminds us that collaboration also brings leaders and followers together to participate in the activity of "organizing" which is a creative endeavor itself. The instructor can set the expectations of a collaborative environment providing some structure, and by allowing the leaner to self-direct some aspects of their learning. The "Final Question" exercise does both.

Self-Directed Learning. The adult Ph.D. learner should be encouraged to pick the concepts at the beginning stage of the exercise and think independently. At the same time, learners of at all stages can still benefit from some structured prompts. The exercise involves both approaches. Synergy, therefore, is achieved because the learner selects some aspects of the learning, and the instructor provides the environment and tools they need to start and finish. In the end, learners make meaning of the process (Merriam \& Bierema, 2014). Creative cognition, then, is also a component of transformation in the Final Question exercise because the learner must combine concepts and build a platform for new ideas (Finke et al., 1992; Steven et al., 
1995). What are the mechanisms, then, that make creativity work and what are some ways to encourage the development of creativity in the learning environment?

Creative Cognition. By using a creative cognition approach, we can encourage creativity in conjunction with other cognitive functions (Finke et al., 1992; Steven et al., 1995; Ward, 2001; Ward et al., 2004; Ward, 2008; Ward \& Wickes, 2009). Creative cognition encourages learners to create new ideas through concept combination, which is where learners are encouraged to play with existing concepts in a way that creates novel or new thoughts (Ward, 2001). Emergent thoughts stretch the creative brain to make the ideas mainstream. Concept modification, on the other hand, is also an avenue for creative thought leading to the modification or new use of existing concepts (Estes \& Ward, 2002; Ward, 2001; Ward et al., 2004; Ward \& Wickes, 2009). Further, concept modification and concept combination seem to follow the same thought processes scholars use to code and categorize concepts in qualitative research or when naming the emergent factors in a factor analysis. For instance, Saldaña and Omasta (2018) note that the underlying principle of qualitative data analysis is "analytic synthesis" or the combination of concepts to create new categories. Also, Creswell and Poth (2018) describe axial coding as a method for organizing data in new and different ways in qualitative data analysis. Ward (2008) argues that we should not ignore domain knowledge either. In fact, it is important to expand knowledge in several fields to increase the repertoire of creative activity. More knowledge areas create more opportunities for concept combination and modification. But Ward (2008) makes it clear that the novel ideas that emerge in creativity are outside simple categorization. For instance, it's one thing to identify the type of leadership an individual expresses at the individual level of analysis, but it is quite a different kind of process to see how the leadership approach changes in various organizational contexts. The Final Question encourages the use of two important domains in Leadership Studies, Organizations and Leadership Theory, to promote this innovation.

The knowledge dimensions and cognitive processes intersect in multiple areas of Bloom's taxonomy, but creativity, in particular, requires the learner to pull together different concepts, find gaps, and create new knowledge. The tool systematically guides the learner and the teacher through all these stages. Each step should help the learner see the learning in progress and help the instructor guide the learning process, which constitutes a metacognitive experience.

\section{Description of the Application}

“The Final Question” asks, "Do leaders change organizations or do organizations change leaders?" It is a simple question, but the first in a series of steps that guide Ph.D. learners on a path to become more creative problem solvers. To answer the question, the learner must first explore two knowledge domains in detail: Leadership Theory and Organization Theory. Next, the learner must combine information from each domain to create novel ideas about leadership action in organizational contexts. The framework I use for the Final Question comes in the following paragraphs. It is not necessary for to include Bloom's learning dimensions, nor the Geneplore dimensions, in the instructions, but going forward I think it is a good idea as it encourages metacognition. The application follows the Geneplore model described by Finke, Ward and Smith (1992), which involves a phase for generating ideas and then for exploring those ideas in different avenues. The following outline helps keep thoughts and the narrative organized 
and focused so learners do not go on tangents and the instructor has a standard by which to evaluate the work (Finke, Ward, and Smith, 1992).

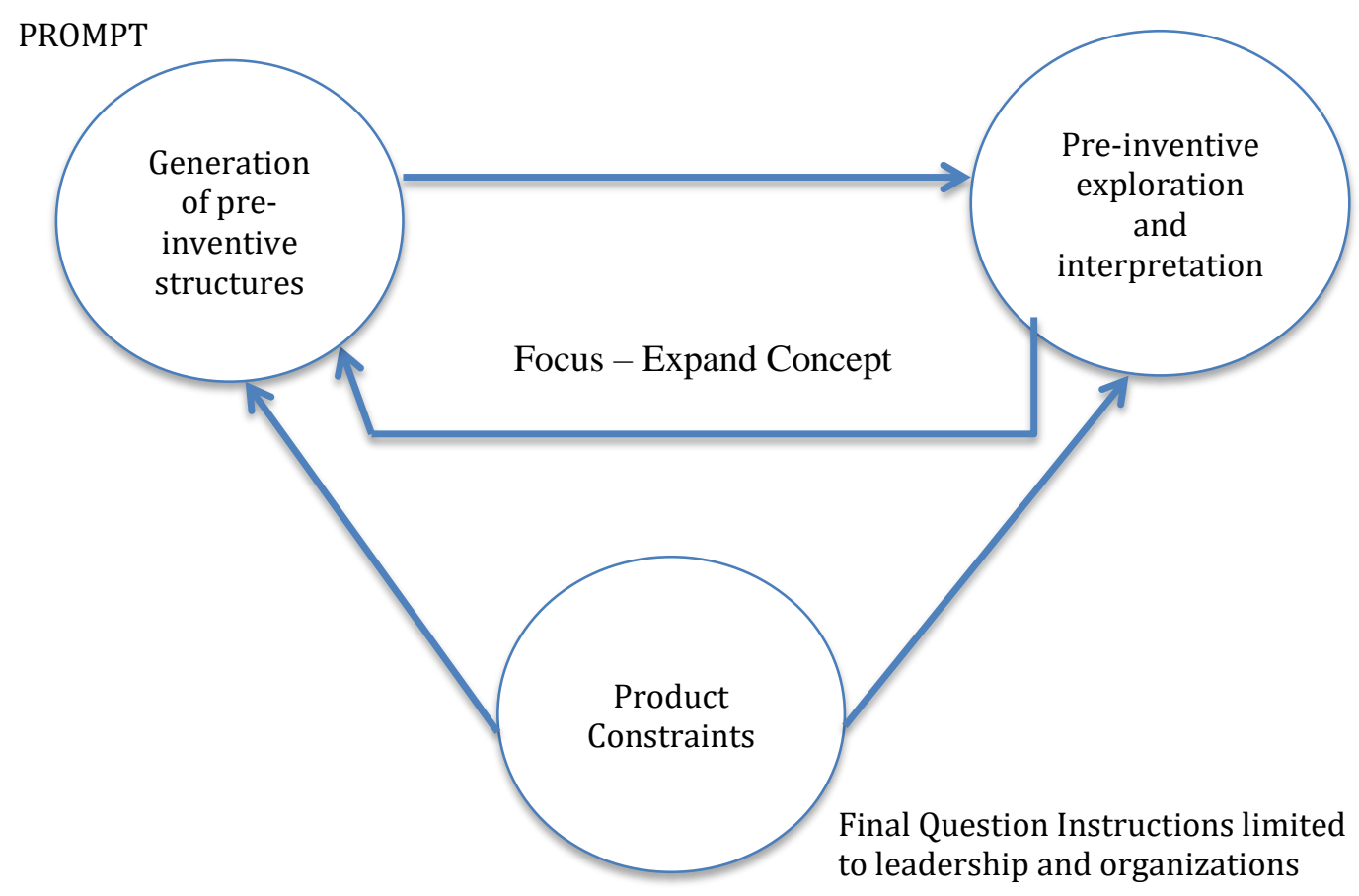

Figure 1. Finke, Ward and Smith's (1992, Page 18) Geneplore model for creativity applied to the Final Question exercise

In Figure 1 the creative process can be prompted by a task, in this case the Final Question. After the prompt, I want the learner to generate pre-inventive structures or the start of new ideas. In the second phase, I want learners to explore and interpret these new structures, and focus the concepts until the concepts are somewhat solidified. Then, eventually, I want learners to explain the concepts to others. In the Final Question, ideas and pre-inventive structures are generated in Sections 1-4 (see below). Because writing a paper is a creative process, learners will likely cycle through generative and exploration phases throughout the life of the exercise. In Section 4, the learner is prompted to create a chart illustrating the convergence of their domain knowledge in leadership theory and their domain knowledge organization theory. The chart adds some constraints, but it keeps the project focused. The blanks spaces in the chart are where leadership theory and organization theory come together and these can be pre-inventive structures. 


\section{Section 1: Introduction. Present The Issue}

- Introduce the question, "Do organizations change leaders, or do leaders change organizations?"

- Explain why the issue is necessary for leadership and the study of organizations. Remember that Leadership is at the individual level of analysis and that institutional theory allows for the examination of multiple dimensions at the same time. Just be sure to let the reader know when you are changing the level of analysis from one stage to the next.

- Provide a summary of the literature you will cover.

- One paragraph.

\section{Section 2: Opening Paragraph}

- Pick four leadership theories (your choice from the literature). It does not matter if you pick a theory you think will fit the context below because you must analyze how the leadership approach works anyway. There will always be weaknesses. There will always be strengths, but I recommend that you use a random method for picking your theories.

- Pick four organizational theories. Again, it does not matter if you pick a perfect match of organizational forms and leadership approaches, you will find strengths and weaknesses no matter what. The organization contexts are constantly changing anyway, and are only snapshots of how things work. A leadership approach will also have to shift. There is no clear pathway, but you will be discovering places where these leadership shifts might take place in context.

- Describe how the leadership approaches might work in the organizational contexts. For example, if you picked rational, natural, open, mixed forms (your choice, but maintain consistency throughout the paper), explain how those contexts might strengthen or weaken the leadership theory and vice versa.

- You should be able to write one or two paragraphs. This is just a summary introduction. The meat of the approach comes in the next sections.

- Bloom Knowledge Dimension: Known facts and concepts

- Bloom Cognitive Dimension: Remembering, Understanding

- Geneplore Phase: Generative

\section{Section 3: Literature Review}

- Review the Four Leadership Theories in Detail

- Consider the four forms of leadership you mentioned in the opening paragraph. Approach this as you would a literature review.

- State the strengths and weaknesses of the theories. But you should avoid writing about the potential interactions with your organizational forms. It's okay to think about them and journal your thoughts. Idea generation begins early and you should never ignore it. But for the sake of this paper, you'll get to the specifics later so don't get sidetracked here.

- Do not write about the organizational theories yet. That comes next.

- Don't forget to cite the authors.

- No Limit on Paragraphs

- Review the Four Organizational Theories You Picked 
- Consider the forms of organizations you mentioned in the opening paragraph, and approach this section just like a literature review as well.

- You will still begin to generate ideas here, but journal about them. Your main task here is to review each organizational theory and its strengths and weaknesses. Remember, you will get to the specifics later so don't get sidetracked here, either.

- Don't talk about leadership in context yet.

- Don't forget to cite the authors.

- In the next section, you will create a concept chart illustrating the characteristics of each organizational type you discussed.

- Bloom Knowledge Dimensions: Known facts and concepts

- Bloom Cognitive Dimensions: Analyzing, Evaluating

- Geneplore Phase: Generative

\section{Section 4: Review of the Theories in Context}

- Move from literature review (analyzing) to evaluation and creation.

- Create a Chart where you will combine concepts, and modify existing concepts from both your Leadership domain and Organization domain. See Figure 2.

- Don't rehash the literature review here. Don't evaluate anymore.

- Now you are free to talk about the subjects of leadership and organizations as if we all know about them.

- Evaluate or critique how each theory might work within various organizational forms and how the organizational structure affects the leader.

- Evaluate the strengths and weaknesses of the leadership forms in light of the organizational types.

- No limits on paragraphs.

- Bloom Knowledge Dimensions: Known facts and concepts, and procedures

- Bloom Cognitive Dimensions: Applying, Analyzing, Evaluating

- Geneplore Phase: Generative to Exploration transition

\begin{tabular}{|l|l|l|l|l|}
\hline & Rational & Natural & Open & Political \\
\hline Leader Member Exchange & & & & \\
\hline Transformational Leadership & & & & \\
\hline Ethical Leadership & & & & \\
\hline Trait Theory & & & & \\
\hline
\end{tabular}

Figure 2: Concept combination/modification chart (examples) 


\section{Section 5: Conclusion, New Concepts}

- Address the gaps in the literature. Which gaps could lead to novel approaches in research? The articles and texts already note these methods.

- Create a chart that shows strengths, weaknesses of organizational forms and leadership styles. Expand the chart you started in section 4.

- Make a statement about which leadership theory might be the strongest in light of the research you just did.

- NAME THE NEW CONCEPT. It doesn't have to be fancy, just make it logical.

- Bloom Knowledge Dimension: Metacognitive

- Bloom Cognitive Dimension: Create

- Geneplore Phase: Generation and Exploration

\section{Outcomes}

This exercise has been an important part of the Organizational Theory course for about 5 years. I think it has become popular among learners. Most of my learners tell me later that the exercise was particularly challenging for them. Some learners reported that the exercise helped them understand the complexities of leadership. While evaluating the work, however, I noticed that the procedure didn't click for all learners. I observed varying levels of creativity, but for the most part, learners created robust charts identifying overlap in theory and new leadership approaches. There were always learners who wrote a traditional report, and skirted the creative aspects of the exercise. There were always learners who avoided creating the chart in section 4 altogether, which was disheartening. They met the goals of the project, but left out the chart. I currently believe they would have used it more if they understood that the chart is actually a great tool for looking at which concepts to combine for a new idea, and which ones to modify. These learners seemed to show less creativity than the learners who took the time to create the chart. One learner told me how she couldn't think about leadership without considering the organizational environment. I believe that is a great outcome.

I once used the chart in section 4 to introduce the course. That seemed to be the best approach. Learners could see my goals and make a mental map about how to achieve the goals. At the same time, some learners wanted to modify the structure for their own understanding. I pushed back when this happened. I try to keep learners on track with the structure. One of my highly competitive learners later told me she was glad I pushed back, because the chart helped her complete the project when she ran into writer's block. Finke, Ward, and Smith (1992) noted that structure is necessary, and though it seems contradictory to the nature of creativity, it is important to set the parameters of creativity when doing research and teaching. We need some standard to evaluate the outcomes anyway, and from my perspective, the chart provides sound evidence of many potential outcomes beyond what the learner creates just for this single paper. This advice seems extremely salient in a leadership and organizations course with a high level of domain knowledge. 


\section{Reflections and Recommendations}

If you use this exercise, my suggestion would be to integrate it tightly into the course and to force communication about it whenever the class meets as a whole. I did not do this very well the first few times, and I think the learners might have missed some ideas. I also recommend having a brief discussion of Bloom's taxonomy, learning theory, and creativity. If Ph.D. learners understand creativity as a higher order function, I think they might shoot for that goal. It wasn't until recently that I began to believe this exercise provides a platform for metacognition. Most of our Ph.D. learners are motivated and interested, so some metacognitive exercise would be beneficial and interesting in the long run. It might also be a good idea to illustrate the Geneplore model to them to help them seek deeper understanding of the process. I have not done this because I thought it might only distract from the project. I don't think there's anything wrong with teaching Ph.D. learners to think about how to think.

Also, when you provide the structured prompt, be sure to engage the learners in a discussion about which Bloom's phase of learning they are in as they go through the exercise. It seems, in many cases, learners sometimes don't understand that people can learn to be creative, and that it does not have to be an innate trait for only a select few. It would also be important for learners to understand concept modification and concept combination along with their learning or organizational theory. Even learners at this stage of their academic career have likely not thought about creativity as an academic discipline and how it could inform curriculum design. 


\section{References}

Anderson, L., Krathwohl, D., Airasian, P., Cruickshank, K., Mayer, R., Pintrich, P. (Eds.). (2001). A taxonomy for learning, teaching, and assessing: A revision of bloom's taxonomy of educational objectives (Abridged ed.). New York: Longman.

Baublits, J. (2014). Promoting creative capacity in followership education. Journal of Leadership Education, 13(4), 146-155. doi:DOI: 10.12806/V13/I4/C15

Bloom, B. (Ed.). (1956). Taxonomy of educational objectives: Handbook I: Cognitive domain. New York: David McKay.

Creswell, J. and Poth, C. (2018). Qualitative inquiry and research design: Choosing among five approaches. Thousand Oaks. Sage.

Estes, Z., \& Ward, T. (2002). The emergence of novel attributes in concept modification. Creativity Research Journal, 14(2), 149-156.

Finke, R., Ward, T., \& Smith, S. (1992). Creative cognition: Theory, research, and applications. Cambridge, MA: The MIT Press.

Jenkins, D., \& Dugan, J. (2013). Context matters: An interdisciplinary studies interpretation of the national leadership Education research agenda. Journal of Leadership Education, 12(3), 15-29. doi:DOI: 10.12806/V12/I3/TF1

Krathwohl, D., \& Anderson, L. (2010). Merlin C. Wittrock and the revision of bloom's taxonomy. Educational Psychologist, 45(1), 64-65. doi:DOI: 10.1080/00461520903433562

Merriam, S., \& Bierema, L. (2014). Adult learning: Linking theory and practice. San Francisco: Jossey-Bass.

Paxton, D., \& Van Stralen, S. (2014). Developoing collaborative and innovatie leadership: Practices for fostering a new mindset. Journal of Leadership Education, 14(4), 15-25.

Saldaña, J. and Omasta, M. (2018). Qualitative research: Analyzing life. Thousand Oaks. Sage.

Steven, S., Ward, T., \& Finke, R. (Eds.). (1995). The creative cognition approach. Cambridge, MA: The MIT Press.

Ward, T. (2001). Creative cognition, conceptual combination, and the creative writing of Stephen R. Donaldson. American Psychologist, 56(4), 350-354. doi: IO.1O37//O003-O66X.56.4.35O

Ward, T. (2008). The role of domain knowledge in creative generation. Learning and Individual Differences, 18, 363-366. doi:10.1016/j.lindif.2007.07.002 
Ward, T., Patterson, M., \& Sifonis, C. (2004). The role of specificity and abstraction in creative idea generation. Creativity Research Journal, 16(1), 1-9.

Ward, T., \& Wickes, K. (2009). Stable and dynamic properties of category structure guide imaginative thought. Creativity Research Journal, 21(1), 15-23. doi:DOI: 10.1080/10400410802633376

\section{Author Biography}

Dr. Tim Atkinson is Assistant Professor and Director of Education in the Department of Internal Medicine, and Instructional Educational Specialist in the Division of Graduate Medical Education. Tim serves in a variety of roles within the Graduate Medical Education framework and the clinical learning environment including coaching medical residents and fellows in leadership, professionalism, learning, and research design. Tim has served in a number of leadership roles in higher education and government from Associate Director to President. Tim also serves as core faculty at the nearby University of Central Arkansas where he teaches Leadership in Complex Organizations and Advanced Qualitative Research. 